\title{
EDITORIAL
}

\section{Calidad, más que una palabra en la formación médica}

\section{Quality, more than word in the medical training}

\section{Frank Lizaraso Caparó ${ }^{1, a, b}$}

Desde hace algún tiempo, escuchamos y leemos de manera frecuente acerca de la calidad, mejora de la calidad, sistema de gestión de la calidad, mejora continua de la calidad, términos usados en diversos escenarios del quehacer cotidiano.

La educación superior, y en especial la que se refiere a la formación médica, no es ajena al análisis e interpretación de lo que significa tener un egresado de y/o con calidad.

La Real Academia Española, en su Diccionario de la Lengua Española, última edición (1), define calidad como: Propiedad o conj unto de propiedades inherentes a algo, que permiten juzgar su valor. Condición o requisito que se pone en un contrato.Estado de una persona, naturaleza, edad y demás circunstancias y condiciones que se requieren para un cargo o dignidad. Nobleza del linaje.

Con lo que se entiende, que la calidad puede y debe ser evidenciada.

Otros autores, se refieren a la calidad como: "cumplir con lo que se ofrece", "conformidad con las especificaciones"; "es dar al cliente aquello que espera" o "producir los bienes y servicios demandados, al menor costo posible para la sociedad" $(2,3)$.

En medicina, y en especial en la educación médica, se requiere hacer bien las cosas, ya que el producto: el egresado, será evaluado, verificado y comprobado por el paciente.

Los sistemas de Gestión de Calidad han tenido un desarrollo extraordinario en el último siglo. En el extremo inicial de dicho desarrollo se encuentra la figura de Vilfredo Pareto y, en el extremo final, tras sucesivas etapas con múltiples tipos de programas, tenemos actualmente el Modelo Europeo de Excelencia EFQM $(4,5)$.

El modelo de excelencia EFQM fue introducido en 1991 como el marco de trabajo para la autoevaluación de las organizaciones y como base para juzgar a los concursantes por el Premio Europeo de la Calidad, creado por la Fundación Europea para la Gestión de la Calidad y entregado por primera vez en 1992 (6).

Nosotros, en la Facultad de Medicina de la Universidad de San Martin de Porres, trabajamos bajo la premisa de la mejora continua de la calidad, para que ambas partes, el médico y el paciente, tengan satisfacción con el producto o servicio recibido.

Considerando a las autoridades académicas, los docentes, y el personal administrativo como parte importante de un Sistema de Gestión de Calidad que gira en función a: Liderazgo, Planificación y Estrategia, Gestión de Personal, Procesos, Recursos, Satisfacción del cliente, Satisfacción del personal, Impacto en la Sociedad y Resultados de la organización (7). Convirtiendo nuestro accionar en una filosofía más que un simple modelo educativo.

Las guías o estándares de calidad, generadas y creadas por diversos organismos, como las normas ISO (International Standard Organization), o los estándares de acreditación, son herramientas que contribuyen a identificar y valorar la calidad. 
El primer modelo de acreditación de la educación médica,se inició en los Estados Unidos por Abraham Flexner, en su histórico informe de 1910:

1. La atención médica debe basarse en el conocimiento de las ciencias biomédicas.

2. Sólo las escuelas de alta calificación deben ser acreditadas para formar médicos.

3. Las escuelas aprobadas deben privilegiar la educación en laboratorios y en la experiencia clínica.

4. Las escuelas sin la calidad necesaria deben ser cerradas.

5. Las escuelas deben estar afiliadas a universidades.

Hoy, ante el crecimiento del número de escuelas o facultades, explicado por la enorme demanda y el fomento a la educación superior en general y la educación médica en particular, se hace necesario evidenciar la calidad y su mejora continua.

Debiendo fortalecer la educación médica con actividades preventivas y promocionales, entendiendo el proceso de atención médica como una acción integral que demuestre que es de calidad por sus mejores resultados en beneficio del paciente.

Es importante disponer de un buen plan de calidad, un mapa de procesos, un cuadro de mando y unos objetivos clave (8).

Si deseamos integrarnos al nuevo ámbito de la educación médica globalizada, estamos obligados, necesariamente, a mejorar permanentemente la calidad de nuestra educación y nuestra práctica médica, por lo que calidad en la formación médica más que una palabra, debería ser considerada como una filosofía de gestión.

\section{REFERENCIAS BIBLIOGRÁFICAS}

1. Diccionario de la lengua española (DRAE), Real Academia Española. Ed 23. ${ }^{a}$, octubre de 2014.

2. Galán M. El Reto de la Mejora en la Educación Superior: Una Perspectiva Europea, Programa de Doctorado: "Evaluación, Mejora y Calidad de la Educación Superior", Universidad de Cádiz, España, enero 2000.

3. Castilla F. Calidad docente en el ámbito universitario: Un estudio comparativo de las universidades andaluzas. Educade 2011, 2: 157172.

4. González M. Biografías de grandes economistas: Vilfredo Pareto. AuladeEconomía.com 2006 [consultado 11-01-2015]. Disponible en: http:// www.auladeeconomia.com/biografias-pareto.htm.
5. European Foundation for Quality Management. EFQM Excellence Model 2010.Bruxelles: EFQM publications; 2009.

6. Ferrando M, Granero J. Calidad Total: Modelo EFQM de Excelencia, 2nd ed., Madrid: Fundación Confemetal; 2008.

7. Sánchez E, Darpón J, Garay JI, Letona J, González R, Pérez MJ. Política de calidad en OsakidetzaServicio Vasco de Salud. Rev Calidad Asistencial 2004;19:189-99.

8. Andreo J. Gestión de Calidad en Medicina Interna. Desde Pareto al EFQM. Med Clin (Barc). 2012;138(7):306-311.

Editor Horizonte Médico

Doctor en Medicina. Médico Cirujano Plástico

Decano de la Facultad de Medicina Humana de la USMP. Lima, Perú. 